ks. Piotr Roszak ${ }^{1}$

Uniwersytet Mikołaja Kopernika w Toruniu

\title{
La vida del embrión según santo Tomas de Aquino
}

Frecuentemente se pueden oír en diferentes debates sobre cuestiones morales relacionadas con los primeros estadios de la vida humana, que la postura de los teólogos medievales - y entre ellos sobre todo de santo Tomas de Aquino (1225-1274) - marcaba el comienzo de vida propiamente humana no en el momento de la concepción, sino un cierto tiempo después (40 días). Se aprovecha dicha postura en las discusiones sobre el aborto, ante todo para subrayar que la mantenida actualmente por la Iglesia es entonces nueva y más radical que la medieval ${ }^{2}$. Por otro lado, para explicar y justificar las ideas tomasianas en torno a la vida del embrión muchos simplemente subrayan su dependencia de los datos biológicos de la tradición aristotélica, sin entrar en cuestiones metafísicas que sin embargo son fundamentales para el pensamiento del Aquinate al respecto y muestran todo lo contrario que se le atribuye hoy. Es de notar una cierta "tensión" entre los principios filosóficos suyos y el estado de una medicina que ya ha sido verificada como inadecuada por la ciencia moderna ${ }^{3}$.

Profesor adjunto de la Facultad de Teología de la Universidad "Nicolás Copérnico" en Toruń, Polonia; profesor asociado de la Universidad de Navarra, España; director de la serie "Scholastica Thoruniensia" de Wydawnictwo Naukowe UMK que publica las monografías y traducciones al polaco de las obras de santo Tomas de Aquino.

2 Cfr. G. Dunstan, The Moral Status of the Human Embryo: A Tradition Recalled, "Journal of Medical Ethics" 1(1984), 38.

Cfr. C. A. Testi, L'embriologia di S. Tommas d'Aquino e i suoi riflessi sulla bioética contemporánea, "Divus Thomas" 1 (1998), 80-105. 
No obstante, puede sorprender a cualquiera que se acerca a los textos del Aquinate su gran conocimiento de la biología de su tiempo aun si ser especialista en la materia. Sin duda, su principal fuente es la filosofía natural de Aristóteles, pero sin descuidar otros autores a los que acude en estos temas, tanto antiguos (Hipócrates, Galeno, los padres de la Iglesia) como a sus contemporáneos que aparecen envueltos en la formula secundum médicos ${ }^{4}$. Una clara muestra de ello son las cuestiones de la vida del embrión (que en el De Potentia ordena en cinco grupos de opiniones médicas), las teorías del "húmedo radical y nutritivo" o la causalidad del semen $^{5}$. Además, no hay que perder de vista que el tema de la generación humana lo trata santo Tomas al hilo de otras cuestiones que le interesan, tanto antropológicas como cristológicas.

Por tanto, para confrontarse con este tema, hay que establecer un panorama más amplio: no hay que fijarse únicamente en las afirmaciones finales, sino en la argumentación y sus presupuestos filosóficos que influyen en la mantenida tesis final. Por este motivo, hemos de considerar primero el tema de la vida y su comprensión por parte del Aquinate (tema eminente filosófico), pasando luego por la identidad del alma que es un "principio de la vida", presentando las etapas de formación del embrión y terminando en la cuestión de cuándo éste es dotado del alma. En cada paso será importante ver en que punto la doctrina del santo se difiere de la de Aristóteles o san Agustín. Pero no podemos olvidar que más que la descripción médica, nos interesan sus principios filosóficos que forman la base para los juicios morales. Este será nuestro itinerario.

\section{El alma como principium vitae: ¿qué es la vida?}

Al intentar presentar el pensamiento de santo Tomas sobre los primeros momentos de la vida humana es importante detenerse primero en la pregunta cómo entiende la vida en si misma. Entre los intentos previos de nuestro autor cabe destacar la de Aristóteles quien mas que definir se inclinaba por describir la vida: "Entre los cuerpos naturales algunos po-

Cfr. In II Sent., d. 30 q. 2 a. 1 ad 3.

Cfr. J. A. Izquierdo, Santo Tomás, ¿maestro de Bioética?, “e-Aquinas” 4 (2006), 9. 
seen vida y otros no; llamamos vida a la capacidad de nutrirse, de crecer y de languidecer por sí mismo"6. En su comentario a este pasaje del libro De anima del Estagirita, santo Tomas observa que es un modo de caracterizar la vida mediante algunas de sus operaciones (ya que el mismo concepto de vida es mas bien abstracto) y que esta lista puede ser ampliada por otras, como la vida sensitiva e intelectiva ${ }^{7}$. No obstante, en este mismo comentario, el Aquinate ofrece una definición formal de la vida que siguiendo la tradición peripatética pone en el centro una capacidad de automovimiento: el ser vivo tiene en sí los principios de su movimiento, es decir su forma ${ }^{8}$. Viven todos aquellos que se mueven por si mismo y no por otro. Dicha forma es la que perfecciona al ser vivo?.

Así percibida la vida, cabe hacer la pregunta: ¿cual es la "razón de vivir"? Tomas la ve en el mismo ser - "el vivir es para los vivientes su ser", señala citando a Aristóteles ${ }^{10}$. El ser es el magis intimum de cualquier viviente y resume lo que es la vida ${ }^{11}$. Como hay diferentes grados del ser, como subrayaba Francisco Canals ${ }^{12}$, también habrá diferentes grados de vida: “[...] vida, considerada ontológicamente, es decir, como grado en la escala de entes, constituida por la participación en el ser" ${ }^{13}$. De ahí que santo Tomas afirmara en la Summa contra gentiles que "el supremo y perfecto grado de vida es el que es según el entendimiento; pues el entendimiento reflexiona de sí mismo y puede entenderse a sí mismo" ${ }^{14}$. Lo resume en una frase: vivere principaliter est sentire vel intelligere ${ }^{15} \mathrm{y}$ solo en secundo senti-

Aristóteles, De Anima II, 412 a 13.

Tomas de Aquino, In de Anima II, lect. 1, n. 9.

In De Anima II, lectio I, n. 9: "Propria autem ratio vitae est ex hoc, quod aliquid est natum movere seipsum, large accipiendo motum, prout etiam intellectualis operatio motus quidam dicitur. Ea enim sine vita ese dicimus, quae ab exteriori tantum principio moveri possunt". Una frase parecida encontramos en Super De Causis, n.18: moveri a seipso est nobilissimus mobilitatis modus, et in hoc consistit ratio vitae.

9 Cfr. V. Possenti, Aquinas: Nature, Life and Teleology, en: M. Waddell (ed.), Restoring Nature: Essays in Thomistic Philosophy and Theology, South Bend 2004.

10 S. Th., I q.18, a.2 , s.c.

11 S. Th., I, q.8, a.1c. Cfr. M. Brown, Aquinas and the Individuation of Human Persons Revisited, “International Philosophical Quarterly" 2 (2003), 167-185.

12 Cfr. F. Canals, Sobre la esencia del conocimiento, Barcelona 1987, 25.

13 Cfr. E. Forment, Lecciones de metafísica, Madrid 1992, 153.

14 ScG, lib. IV, cap. 11.

15 S. Th., I, q.8, a.2c. 
do es una actividad ${ }^{16}$. La vida contiene en sí una actualización (se agunt ad motum $)^{17}$, de ahí que también una auto-perfección. Merece la pena tener en cuenta esta visión de la vita que propone santo Tomas: desde los movimientos, por el nivel sensible hasta la vida de intelección ${ }^{18}$.

Al resumir, vemos claramente una doble consideración de la vida en santo Tomas: sustancialmente, el tipo de ser propio del viviente, que jamás puede faltar en él mientras permanece la forma que le da el ser (de ahí que vivere viventibus est esse ${ }^{19}$ ); y accidentalmente, en sentido de multiformes acciones vitales. De este modo la vida se manifiesta en las opera vitae ${ }^{20}$.

Para el tema que nos ocupa es importante fijarse en una afirmación clave del Aquinate que sostiene que para los cuerpos, su "principio de vida" (principium vitae), es el alma gracias a la cual pueden vivir naturali$t r^{21}$. Este principio de vida le llega al cuerpo per modum formae ${ }^{22}$, pues es la forma que da el esse ${ }^{23}$ la perfección de todas las perfecciones. Se instala en la esencia como principio primero de obrar.

De ahí que para entender el estatus del embrión humano y su desarrollo habrá que prestar atención al tema del alma como tal, pues es ella la que naturam humanam integrat et constituit ${ }^{24}$. Es la problemática que ampliamente trata el Aquinate en la Suma de teología, particularmente en dos cuestiones, la 75 y la 76 de la Prima Pars. Allí defiende su tesis que el alma es forma sustancial del cuerpo (forma corporis), que constituye con el cuer-

16 Desarrolla esta cuestión, criticando la interpretación de la vida en cuanto "actividad immanente" J. E. Royce, Life and Living Being, “The Modern Schoolman” 37 (1960), 213-234.

17 S. Th., I, q.18, a.1c.

18 S. Th., I, q.18, a.2c: "Pues el nombre vida está tomado de algo aparente de una cosa como es el moverse por símisma. Sin embargo, no se da para indicar eso, sino para indicar la sustancia que le corresponde según la naturaleza que conlleva el moverse por sí misma, o, también, y de algún modo, su impulso para actuar. Según esto, vivir no es más que el ser en tal naturaleza; y vida no significa más que lo mismo, pero en abstracto; como carrera significa en abstracto lo mismo que correr. De ahí que vivo sea un predicado sustancial, no accidental".

19 De Anima, 4, 415b 13.

20 Cfr. S. Th., I, q.77 a.1.

21 ScG, lib. III, cap. 139: "Vivit enim corpus naturaliter per hoc quod animae unitur, quae est ei principium vitae".

22 In III Sent., d. 2 q. 1, a. 3, qc. 2, ad 2. "Ad secundum dicendum, quod ad hoc quod corpus vivificetur, requiritur quod sibi conjungatur principium vitae per modum formae, ut ex eis efficiatur una natura communis".

23 In De anima, a. 10 ad 2.

24 In II Sent., d. 31 q. 2 a. 1 ad 2. 
po una sustancia completa y es un principio de vida en los entes vivos ${ }^{25}$. Otro cuerpo no puede ser el principio de vida, tiene que serlo el alma. Para santo Tomas, el cuerpo y la forma llegan a ser en el mismo momento, pues no existe un cuerpo humano sin la forma sustancial (solo se puede designar así por la analogía).

Como hay diferentes formas de vida, habrá también diferentes almas: de ahí que en el tema de la generación humana, comprendido como un motus ad formam, Tomas se apoya en el modelo aristotélico ${ }^{26} \mathrm{y}$ afirma la sucesión de almas (nutritiva-sensitiva-intellectiva). Cuando el proceso del desarrollo llega a su culminación, Dios infunde el alma racional, pues dicha alma no es educida de la materia como en el resto de criaturas materiales. Cabe advertir aquí, antes de entrar en detalles, que en el sistema tomasiano el embrión es vivo y mantiene sus actividades de nutrición y crecimiento, sin embargo no es una vida específicamente humana ni de ningún otro animal. Las actividades vitales del embrión se deben a su alma, aunque su desarrollo no es simplemente la actividad de su alma, sino actividad de sus padres que viene "desde fuera", a través del semen ${ }^{27}$.

\section{Transmitir la vida y virtus generativa humana. ¿Quién da la vida?}

Para santo Tomas, la transmisión de la vida (generatio) supone una gran dignidad para el hombre, porque aunque un ángel es más una imagen de Dios por su naturaleza que el hombre, sin embargo en otro aspecto es el hombre más imagen de Dios, precisamente por cuanto "el hombre nace del hombre, como Dios nace de Dios" ${ }^{28}$. En la perspectiva del Aquinate los padres no son "autores de la vida" por razón de lo expuesto arriba: si el alma es creada directamente por Dios y es ella la "portadora" de la vida, es mas

25 R. Pasnau, Thomas Aquinas on Human Nature. A Philosophical Study of "Summa Theologiae" $1^{\text {a }}$ 75-89, Cambridge University Press, Cambridge 2002.

${ }^{26}$ La influencia de Aristóteles y su biologia (De generatione animalium y De anima) no es solo de 'marco', sino también incluye los detalles, aunque no lo sugiere pocas veces (relativamente) citada la auctoritas del Filosofo en la "Summa". Cfr. P. Porro, Tommaso d'Aquino: un profilo storicofilosofico, Carroci, Roma 2012.

${ }_{27}$ Cfr. S. Th., I, q.118, a.1, ad 3.

${ }_{28}$ S. Th., I, q.93, a.3c. 
preciso hablar de la con-incidencia entre la virtus generativa humana, expresada en sus padres y la acción creadora de Dios. Por este motivo, santo Tomas llama a Dios el auctor vitae y presenta interesantes reflexiones sobre el sentido de la "paternidad" de Dios. En el comentario a la Carta a los Efesios observa: certe omnis virtus generativa in nobis est a Deo ${ }^{29}$. Esto no contradice que los padres son los verdaderos progenitores del hijo, pues son los que - a través de la fuerza formativa (virtus formativa) del semen, comprendida como cierto impulso del alma misma del que engendra ${ }^{30}$ unida a la causalidad del menstruo materno, preparan la creación del alma por parte de Dios. De ahí que considerada de esta manera la colaboración de los padres puede ser designada como "pro-creación". Es un ámbito donde confluyen y coordinan las voluntades de los padres con la voluntad de Dios, es decir, el acto humano con el acto divino.

\subsection{Conceptio humana}

La fuerza generativa de los padres (virtus generativa) es transmitida por el semen al embrión que inicia una especie de "reacción de cadena" con el fin de su desarrollo ${ }^{31}$. Queremos detenernos ahora en analizar como percibe santo Tomas el papel de cada uno de los padres en la concepción de una vida. Sin duda, la comprensión de la concepción marca luego el modo de entender el desarrollo del embrión en las primeras etapas de la vida.

El Aquinate analizando el papel de cada uno de los padres observa que "la potencia generativa en la hembra es imperfecta con relación a la que existe en el macho. Y por eso, así como en las artes la inferior dispone la materia, y la superior hace aparecer la forma, como se dice, en el libro II Phys., de modo semejante la virtud generativa de la hembra prepara la materia, y la virtud activa del macho da forma a la materia preparada" ${ }^{32}$. La

\footnotetext{
In Eph., cap. III, lect. 4.

30 S. Th., I, q.118 a.1 ad 3: "quasi quaedam motio ipsius animae generantis".

31 Cfr. D. A. Jones, Thomas Aquinas, Agustine and Aristotle on "delayed animation", "The Thomist" 76 (2012), 7.

32 S. Th., III, q. 32 a. 4 ad 2: "potentia generativa in femina est imperfecta respectu potentiae generativae quae est in mare. Et ideo, sicut in artibus ars inferior disponit materiam, ars autem superior inducit formam, ut dicitur in II Physic. ita etiam virtus generativa feminae praeparat materiam, virtus vero activa maris format materiam praeparatam".
} 
fuerza generativa se encuentra en el semen masculino ${ }^{33}$ que ejerce el papel - dentro del marco aristotélico - de la causa eficiente, formal y final. La sangre menstrual de la mujer es la causa material, pues es en ella donde acontecerá, según el Aquinate, la concepción: su papel es aportar una materia apta ad conceptum ${ }^{34}$. Tomas utiliza la metáfora (de origen aristotélico) del mundo marítimo: la relación entre ambos se parece al arte de construir barcos que necesita la madera para formar una nave ${ }^{35}$.

De esta manera, es de notar que para santo Tomas el proceso de la generación humana no empieza en la concepción, sino ya en el semen del padre (que se mantiene vivo hasta 40 días, según el), marcando así todo un periodo de las primeras etapas de la vida del embrión, que pueden denominarse generalmente como la concepción. Es importante subrayar este punto ya desde el principio, pues crea un marco de pensamiento que no hay que perder de vista y abre posibilidades de vincular las ideas del Aquinate con los logros de la biológica moderna, ya que el Angélico utiliza el término de la concepción, como vemos, en sentido bastante amplio.

Al fijarse en la fuerza del semen, el Aquinate lo describe en términos de "potencia" y nos virtus generandi: aunque se deriva del cuerpo del hombre, no obstante no pierde la potencialidad de todo hombre, sino mantiene la capacidad de crecer un entero nuevo cuerpo humano. Es la fuerza que viene, subraya santo Tomas, del alma del generador y se parece a un llamado (quamdiu) "calor del alma"36. De ahí que el semen masculino contiene spiritus vitalis, de naturaleza parecida al calor que emiten los cuerpos celestes ${ }^{37} \mathrm{y}$ no puede ser considerado como una causa separada (semen non est principium separatum ${ }^{38}$.

33 Sermo Exiit qui seminat, pars 2: "Virtus generativa speciei manet in semine".

34 S. Th., III, q.31 a.5.

35 In III Sent., d.3 q.3: "sicut ars compaginans navim ei quae complanat ligna".

36 Cfr. In II Sent., d. 8, q. 1, a. 4, qc. 2, s.c. 2: "Semen non habet virtutem generandi nisi quamdiu calor animae in eo retinetur, quem oportet exhalare per magnam distantiam delatum".

${ }_{37}$ No hay que perder de vista la influencia de la cosmología medieval, apoyada en los "elementos" del universo, que se hace notar en santo Tomas, aunque claramente no constituye un discurso principal: cfr. S. Th., I, q.118 a.1 ad 3: "En este espíritu se contiene cierto calor, derivado de la virtud de los cuerpos celestes, porque, como se dijo, los agentes inferiores obran en orden a la especie, también por virtud de aquellos. Y, justo porque en este espíritu se juntan la virtud del alma y la virtud celeste, se suele decir que «al hombre lo engendran el hombre y el sol conjuntamente». En cambio, el calor de los elementos funge de instrumento respecto a la virtud generativa del alma, como también respecto a la virtud nutritiva, como se dice en el II De Anima".

38 Cfr. S. Th., I, q.115, a.2, ad 4. 
En un texto de su "Comentario a las Sentencias", a modo de resumen, presenta una triple comprensión de lo que es la concepción humana, tomando como criterio el curso del tiempo. La conceptio humana no se limita a un solo acto, sino forma todo un conjunto. En la concepción ocurre, según su visión, lo que es una acción "principal" que consiste en la "formación y organización del cuerpo" cuyos protagonistas son los padres (el agente es el padre y la madre suministra la materia). Otra acción que se puede ver en la concepción humana es de carácter "preparatorio": se trata de preparar la materia a la concepción. Esto tiene lugar en la madre que dispone de una cierta virtus agens. La tercera acción - o etapa de la concepción, si uno quiere - es la que ocurre después de la principal actio y que destaca el gran papel de la madre de la que depende como va a crecer el embrión: como un sitio influye a la bondad de la generación, así la "la buena disposición materna actúa para la disposición de la prole", quasi praebens fomentum, añade santo Tomas ${ }^{39}$. En otro texto llegará a decir "mulier est principium prolis quae nascitur de viro" ${ }^{40}$. La concepción dura hasta que no termine la acción principal, es decir, a la formación y la organización del cuerpo.

Al describir el momento de la concepción humana, santo Tomas acude a un par de términos que le sirven para oponerse a algunas opiniones que ven dos "nacimientos" humanos de modo radicalmente opuesto: uno in utero que correspondería a la otorgación del alma racional y otro ex utero que significaría la dotación de cuerpo. Tomas rechaza esta opinión, porque en el nacimiento in útero ya aparecen corpus et anima y además conjuncti ${ }^{41}$. Esta distinción es más bien adecuada, observa nuestro autor, porque se asimila a lo que en la Iglesia es el bautismo y confirmación ${ }^{42}$.

39 In III Sent., d.3 q.3 a.1: "Dicendum videtur, quod in conceptione prolis invenitur triplex actio. Una quae est principalis, scilicet formatio et organizatio corporis; et respectu hujus actionis, agens est tantum pater, mater vero solummodo ministrat materiam. Alia actio est praecedens hanc actionem, et praeparatoria ad ipsam; cum enim generatio naturalis sit ex determinata materia, eo quod unusquisque actus in propria materia fit, sicut in II De Anima dicit Philosophus, oportet ut formatio prolis fiat ex materia convenienti, et non ex quacumque. Unde oportet esse aliquam virtutem agentem, per quam praeparetur materia ad conceptum. [...]. Tertia actio est concomitans, vel sequens actionem principalem. Sicut enim locus facit ad bonitatem generationis; ita et bona disposition matricis operatur ad bonam dispositionem prolis, quasi praebens fomentum".

${ }_{40}$ Cfr. F. Hartel, Femina ut imago Dei: In the Integral Feminism of St. Thomas Aquinas, Roma 1993, 83-89.

${ }^{41}$ In IV Sent., d. 6 q. 1 a. 1 qc. 1 co.

${ }_{42}$ In IV Sent., d. 42 q. 1 a. 2 ad 1: "El estado del embrión que nace in útero caracteriza la debilidad quod non possit extra exponi sine periculo de ahí que asimila al bautismo y cuando ya nace de útero, pudiendo expresarse en lo exterior, se hace símil a la confirmación". 


\subsection{Embarazo}

El embarazo no aparece como tema directo en las consideraciones de santo Tomas, sino indirectamente, sobre todo para resolver unas cuestiones éticas o teológicas concretas. Aunque el embarazo en lenguaje bíblico (inspirado por la Génesis) se describía como motivo de aflicción para la mujer, sin embargo considerado en sí mismo no es asít3 ${ }^{4}$. Las afirmaciones acerca del embarazo - gravidus en terminología tomista - hacen referencia a san Agustín (matres gravidae sunt foetibus) que sirven para explicar la naturaleza de las razones seminales, útiles a la hora de explicar los milagros ${ }^{44}$.

El embarazo crea un vínculo especial entre la madre y el embrión: es la conclusión a la que llega el santo cuando se pregunta si es cierto que son las madres que mas aman a sus hijos que los padres. Ponen "mas de su parte", explica el Aquinate, en la generación de los hijos (aportando la materia), pero "mas de lo que constituye al hijo" reciben del padre que da su forma ${ }^{45}$.

\section{Desarrollo del embrión: un esbozo de la embriología tomista}

En la descripción de la vida humana pasamos ahora a analizar la situación del embrión. Es preciso leer los textos del nuestro autor en un marco general que percibe el desarrollo del embrión en las primeras etapas no como un auto-desarrollo, como si en el mismo, desde la concepción estuviera una fuerza vital. A diferencia de los Padres de la Iglesia (p.ej. Gregorio de Nisa), Tomas no admite en el embrión una fuerza interior transformativa, sino la localiza en el padre: "la formación del cuerpo se realiza por la potencia generativa no del que es engendrado, sino del padre que engendra mediante el semen, en el que obra la fuerza formativa derivada de la vida del padre" 46 .

${ }_{43}$ Cfr. S. Th., II-II, q. 164 a. 2 ad 2: "La multiplicación de los hijos se toma como castigo para la mujer, no en cuanto a la misma procreación de los hijos, que hubiera existido también sin el pecado, sino por el cúmulo de aflicciones que se siguen, para la mujer, del hecho de llevar al feto concebido".

${ }_{44}$ Cfr. S. Th., I, q.115, a.2, ad 4; De Veritate, q. 5 a. 9 ad 8.

45 In III Sent., d. 29 q. 1 a. 7 ad 4.

46 S. Th., III, q.33, a.1, ad 4. 


\subsection{Seis etapas del desarrollo del embrión}

Un cierto orden de las etapas del desarrollo del embrión humano, tal como lo comprendía santo Tomas, nos lo transmite su comentario al libro de Job, meditando las palabras: “AAcaso no me derramaste como lechey me cuajaste como el queso? Me revestiste de piel y de carne y me tejiste con huesos y tendones" (Job 10,10-11). Aunque no surge al análisis directo del fenómeno, sin embargo puede servir de un esquema general. Siguiendo sus observaciones, ampliaremos dicha perspectiva con otros textos del Santo, sobre todo del Comentario a las Sentencias (In III Sent., d.3, q.5, a.2), de las cuestiones De Potentia y de diversos pasajes de la Suma de teología $a^{47}$.

La primera etapa de la vida del embrión la llama el Aquinate "resolución del semen" (resolutio seminis) y dura unos seis días. Empieza por el momento de coito en que el semen masculino se depone en la vagina y es atraído hasta el útero. El semen masculino realiza su virtus formativa en el menstruo, mezclándose con él, y actuando según cierto "programa" dinámico que santo Tomas llama razón seminal (ratio seminalis) y que se parece, como sugiere R. Busa ${ }^{48}$, en cierto sentido a lo que hoy llamaríamos códice genético. De esta manera surge la corpulenta sustancia del embrión que aparenta en forma de semen ${ }^{49}$, aunque el mismo seguirá operando durante todas las transformaciones de esta corpulenta materia ${ }^{50}$.

El segundo estadio es la compactación de la masa corpórea (compactio massae corporeae) en el útero de la mujer donde actúa la fuerza nutritiva del semen y así transforma el menstruo en carne. La sustancia corpulenta de la primera etapa pasa a ser ahora "masa sanguínea". El semen despierta el alma vegetativa que se encontraba "adormecida" en el menstruo $0^{51}$.

47 En esta parte que explica los etapas de la vida del embrión nos servimos de la exposición de la doctrina del Aquinate de J. A. Izquierdo, Santo Tomás, ¿maestro de Bioética? ya mencionado arriba.

${ }_{48}$ Cfr. R. Busa, Per S. Tomás "ratio seminalis" significa "codice genetico": problemi e metodi di lessicologia e lessicografia tomistiche, en Atti del'VIII Congresso Tomistico Internazionale, Città del Vaticano 1982, v.I, pp. 437-451.

49. In II Sent., d.30 q.2 a.2 ad 1.

50 De Potentia, q.3 a.11 ad 8: "licet corpulenta materia, ex qua conceptum formatur, multoties per generationem transmutetur, non tamen virtutis praedictae subiectum destruitur".

${ }^{51}$ Lo explica con estas palabras santo Tomas In II Sent. d.18 q.2 a.3.: "el poder formativo del semen convierte la materia preparada por la mujer en la sustancia de los miembros, análogamente al proceso de transformación del cuerpo durante el crecimiento, como se dice en el Libro XV de 
La materia corpulenta del embrión encerrada en una membrana consigue una consolidación y consistencia que permitirá pronto diferenciarse en las partes que es ya la tercera etapa, la de distinctio organorum: "su consistencia y fuerza proviene de los nervios y los huesos, mientras que la carne y la piel los encierran por fuera" 52 .

En esta fase acontece la formación del embrión (formatio et organizatio), que abarca las varias partes del cuerpo ordenadas a las diferentes operaciones vitales, propias para el alma humana ${ }^{53}$. Esta diversidad de los órganos es necesaria por la diversidad de las operaciones del alma y es un signo de la perfección ${ }^{54}$. De esta manera el embrión entra en las últimas etapas de preparación para recibir el alma espiritual. Esta aparición de los órganos se rige por un cierto orden. El primero en generarse es el corazón y el celebro, a veces identificados con la partícula vel ${ }^{55}$. Son órganos esenciales que permiten hasta definir al hombre ${ }^{56}$. No obstante, es el corazón que recibe por parte de santo Tomas la afirmación del primum animatum ${ }^{57}$, porque toda la vida se fundamenta en torno a este órgano.

Tal preparado el embrión es capaz de recibir el alma racional que es una etapa que describe el Aquinate como animatio fetus. La condición necesaria para que llegase este momento es una correspondiente dispositio materiae, que se hizo realidad a través de las generaciones y corrupciones

los Animales. Y en la medida que los órganos alcanzan mayor perfección, el alma, que primero estuvo en potencia, empieza a volverse más y más en acto en el semen; de tal modo que el concebido primero participa las operaciones de la vida nutritiva, y entonces se dice que vive la vida de la planta, y así sucesivamente hasta cuando alcanza a la semejanza completa con el generante".

52 In Iob cap. X.

53 "Por eso, para cumplir sus operaciones necesita muchos órganos, de los que las potencias del alma constituyen los varios actos. La vista por ejemplo es acto del ojo, el oído de la oreja, etcétera. He aquí porqué los animales perfectos tienen la máxima diversidad de órganos y en cambio las plantas tienen muy pocos" (Gent., II, 72).

54 "Et dicitur corpus organicum, quod habet diversitatem organorum. Diversitas autem organorum necessaria est in corpore suscipiente vitam propter diversas operationes animae" (In II De Anima, lect. 1).

55 "Huiusmodi autem sunt partes principales corporis, in quibus primo consistit forma, scilicet anima; scilicet cor, vel cerebrum" (In VII Met., lect. 10 n. 1488), aunque a veces queda mas la primacia del Corazon ("In formatione embrionis, cor ante omnia membra generatur" II Sent., d. 12 q.1 a.2 ad 6).

56 De Potentia, q.9 a.4: "Hoc nomen homo significat aliquid habens cor et cerebrum et huiusmodi partes, sine quibus non potest esse corpus animatum anima rationali”.

57 S. Th., I, q.76 a.1. 
descritas arriba. Es el momento de la intervención divina directa que crea (ex nihilo) el alma en el hombre. Junto con esto, añade santo Tomas en el comentario a Job, el embrión recibe unas semillas que serán las disposiciones que van a ser distintivas de la persona: "Y simultáneamente con el alma racional se infunden en el hombre, por intervención divina, algunos principios de acción en semilla (seminaria» virtutum); algunos comunes a todos y otros propios de algunos, por los que algunos hombres resultan dinámicamente dispuestos para una acción y otros para otra". A esta etapa debemos prestar más atención en el siguiente punto.

La última fase es la que corre entre la dotación del alma por Dios hasta el nacimiento. El feto se desarrolla gracias a la virtud de la alma intelectiva que asume las operaciones de la vegetativa y sensitiva. Lo sistematiza muy bien una cita del Compendium Theologiae:

"En cambio, la forma sustancial no admite un más y un menos, ya que el ser sustancial de cada cosa es indivisible. Por eso la generación natural no procede continuamente por muchos medios que pasan de lo imperfecto a lo perfecto, sino que a cada grado de perfección le debe acompañar una nueva generación y corrupción. Así en la generación del hombre, lo concebido, primero vive la vida de la planta, con un alma vegetativa. Después, eliminada esta forma por corrupción, adquiere con otra generación una cierta alma sensitiva y vive la vida del animal. Finalmente, eliminada esta alma por otra corrupción, se introduce como forma última y completa el alma racional, que contiene toda la perfección habida por las formas precedentes" 58 .

\subsection{Cuestiones acerca la "animación humana retardada" en Aquinate}

La generación del ser humano debe regirse por tres reglas fundamentales para santo Tomas: privatio, generatio et corruptio ${ }^{59}$. De ahí que la llegada del alma racional supone una etapa de la vida totalmente diferente, pues las dos almas anteriores - vegetativa (correspondiente a las dos primeras etapas) y sensitiva - no superaban las potencialidades de la mate-

\footnotetext{
Comp. Theol., I, 92.

59 Cfr. M. Caponnetto, Santo Tomás y el problema de la generación humana. "e-Aquinas" 4/2 (2006) 42-62.
} 
ria, siendo formas transitorias deducidas del semen (en caso de la sensitiva educidas de la potencialidad del embrión) ${ }^{60}$. Todo lo contrario del alma intelectiva que supera el poder del semen y debe ser infundida directamente por Dios: su estatus es el de substantia per se subsistens, non ex materia ${ }^{61}$. Ya lo intuía Aristóteles cuando decía que "sólo la inteligencia entra desde fuera y solo ella es divina"62. A través de la creación del alma se realiza la donación del ser que es el acto del ser del alma, comunicado al cuerpo. Dicha alma, siendo inmaterial no puede ser engendrada por los padres, sino por Dios, cuando finalice el proceso del desarrollo.

De este modo, santo Tomas toma la postura de la creación directa, diferenciándose sobre todo de la corriente de "traducianismo", representada por Tertuliano, que mantenía la opinión que el alma es generada por los padres, pero también del platonismo que afirmaba la prexistencia de las almas y su caída. Analizando los textos, se ve que el Aquinate más sigue la opinión de san Jerónimo, que aparece, además, como una de las auctoritas. Tomas era consciente también de las dudas de Agustín que se expresaba en De origine animae mas como quien sigue investigando que ya acertando $0^{63}$. Para apoyar su opinión y calificarla de dogma cristiano, santo Tomas acude a Genadio de Marsella y su De ecclesiasticis dogmatibus del siglo V, el autor que dependía de san Jerónimo. Su tesis, mas clara que la de san Agustín, permitió a los medievales (Pedro Lombardo) ver en dicha doctrina la formulación dogmática ${ }^{64}$.

El proceso embriogenético describe la sucesión de almas en término de "remplazamiento", aunque el carácter de dicho salto de especie puede interpretarse, fijándose en algunos textos del Aquinate, como mas bien lógico, según el ordo natura $e^{65}$. Como señala Fabrizio Amerini, la postura de santo Tomas, comparada a las opiniones de los teólogos de su tiempo, se caracteriza por una cierta originalidad marcada por una discontinuidad de

60 Tomas lo percibe incluso como generaciones intermedias, pero al mismo tiempo advierte de que no se perciba como una alteratio al modo como una luz encendida se intensifica en continuidad hasta alcanzar su plenitud - cfr. ScG II, 89.

61 In Ps., 32, n.14.

62 Aristóteles, De Gener. Animal., B, 3, 736b 27-28.

63 De Potentia, q.3, a.10 ad 1.

64 D. A. Jones, The soul of the embryo..., 106.

65 In II Sent., d.4, q.1, a.3, ad 1. 
la generación humana: la sucesión de las formas es la única posibilidad que queda si defiende la tesis de la forma sustancial que no puede ser ni completada ni perfeccionada (siendo inmortal) ${ }^{66}$. Al situar la infusión del alma no en el momento de la concepción, santo Tomas muestra su dependencia de Aristóteles y su comprensión del alma que viene al cuerpo físico orgánico que tiene la vida en potencia y una señal de esto es la aparición de los órganos ${ }^{67}$. Por otro lado, el fin de la concepción para el Aquinate es un embrión animado racionalmente, capaz de ejercer las funciones vitales.

\section{El momento de animación racional}

En la Suma de teología no lo indica directamente, como lo hizo en el comentario a las Sentencias, donde puso que la concepción del hombre no se completa antes de 40 días (para san Agustín 46 para ambos sexos) y de la mujer antes de $90^{68}$. ¿De donde vienen estas cifras? Los autores, como David Jones $^{69}$, muestran que provienen ya de la tradición hipocrática (aunque el mismo Hipócrates estimaba los días en 35 y 42) con la que se identifica Aristóteles, quien afirma que en torno a los 40 días ya se podría hablar de un cuerpo bien formado (que testifican los restos de los embriones abor$\operatorname{tados}^{70}$ ) y unos tres o cuatro meses después de la concepción se puede notar el primer movimiento en el útero. La postura del Estagirita en la Historia Animalium parece ser mas bien reconciliadora: según el, los primeros movimientos del embrión masculino aparecen a los 40 días (a la parte derecha del útero), mientras que el femenino a los tres meses (90 días) ${ }^{71}$.

Es de notar también la posible influencia filosófica griega en la traducción o mejor dicho en la interpretación (pues hay notables diferencias con

66 F. Amerini, Tommaso dAquino. Origine e fine della vita humana, ETS, Piza 2009, 105.

67 Algunos como Baztan, subrayan recientemente que al situar la infusión en el momento de la concepción no se trataría necesariamente de caso de perfeccionamiento de la forma sustancial que tanto quiere evitar el Aquinate. Cfr. A. G. Wilson, Thomas Aquinas and Henry of Ghent on the Succession of Substantial Forms and the Origin of Human Life, "Proceedings of the American Catholic Philosophical Association" 64 (1990) 117-131.

68 In III Sent., d.3, q.5, a.2.

69 D. A. Jones, The soul of the embryo, 27.

70 Historia Animalium 7.3583b 3-5, 15-23.

71 Otra postura toma Norman Ford que interpreta el texto del Aristóteles en sentido que el criterio es la aparición de los órganos sexuales. Cfr. N. Ford, When I did begin..., 28. 
el texto hebreo) que hace Septuaginta de un texto del Éxodo $(21,22-23)$ donde se especifica el género de castigo si por causalidad uno provoca el aborto de la mujer (en la pelea de dos hombres): si el cuerpo del embrión estaba ya formado (tenia el eikon, propiamente dicho) debe considerarse como homicidio, con el castigo "vida por vida", y si era informado se establece una recompensa. Sin duda, la influencia de la Septuaginta para los primeros cristianos y el pensamiento teológico patrístico y medieval era enorme, lo cual se nota en el mismo Agustín o Aquinate. Por otro lado, la tradición judía (Talmud) apunta hasta la distinción entre formado e informado, fijando 40 días y 80 días, lo cual viene enraizado en la ley de la purificación después del nacimiento (Lev 12, 2-5).

El estatus del embrión, según el Filósofo cuya opinión sigue santo Tomas, no pertenece a ninguna especie (para defender lo que mantenía Aristóteles, que prius animal quam homo), solo por una "reducción" puede ser llamado hombre ${ }^{72}$. Como explica en De Potentia, es el embrión del ser humano, aunque en si mismo no es todavía un ser humano antes de los 40 días. Con esto se abre un debate sobre desde cuando podemos hablar de la persona humana. Santo Tomas lo indica al momento de la dotación del alma, aunque no pueda ejercer su racionalidad. Este acto hace del embrión un ser humano, aunque todavía el alma no puede obrar como hombre. Acudiendo a una útil distinción tomasiana, el embrión posee ya actos del hombre (actus hominis), aunque no puede todavía ejercer los actos humanos (actus humanus). De ahí que el embrión no es un ser perfecto, pero está en el camino hacia la perfección ${ }^{73}$. No obstante, esto abre una cuestión más profunda y muy filosófica, sobre la identidad del embrión.

\subsection{Identidad del embrión}

Tomas no admite la continuidad formal del proceso de generación, que la forma se mantenga numéricamente la misma, mientras que la virtud formativa sí, permanece a lo largo del proceso. Al percibirlo así, como pro-

72 Cfr. L. Cova, "Prius animal quam homo". Aspetti della embriologia tommasiana, en: C. Crisciani; R. Lambertini; R. Martorelli Vico (eds.), "Parva naturalia”. Saperi medievali, natura e vita. Atti dell'XI convegno della Società Italiana per lo Studio del Pensiero Medievale, Atti, 44: Istituti Editoriali e Poligrafici Internazionali, Pisa-Roma 2004, 357-378.

73 De Potentia, q.3, a.9, ad 10. 
ceso de generación y privación, como defender entonces la identidad del embrión? Pero son cosas distintas, continuidad e identidad, pues la continuidad puede abarcar una parte de la materia o algo que queda inmutable. Tomas al mantener la discontinuidad parece hacerlo mas bien en plan formal que material. El embrión de los primeros momentos es formalmente diferente del que ya tiene algunos órganos. El tema de la identidad radica en dos cuestiones: cuando el embrión vive por su cuenta y no por la madre, y luego de la identidad numérica trans-temporal, que permite identificar el niño recién nacido con el embrión. En la llega del alma, el día 40, el proceso de "generación" está terminado formalmente y empieza el "crecimiento". El embrión es un ente distinto de la madre, aunque sigue en seno materno (Tomas lo considera pensando en el pecado original y bautismo: si al bautizar la embarazada el efecto llega al del seno ${ }^{74}$. El problema del Aquinate es como se pude hablar de la continuidad material sin la identidad formal,

Siguiendo a Amerini, que analiza profundamente las exigencias del pensamiento metafísico del Aquinate y observa que en Aquinate, en cuanto al embrión se puede partir de tres tipos de identidad (dejando la formal, pues claramente no es aplicable al caso por tratar la generación como privación de formas): del género, de la materia y la de funciones vitales. Para entender mejor a que tipo podríamos referirnos basta acudir al ejemplo que pone el Aquinate, el de la ciudad, que no pierde su identidad aunque haya cambio de personas que la forman ${ }^{75}$.

En plan general hay que reconocer que santo Tomas no precisa el como sucede el remplazamiento de formas y absorbimiento de funciones que pasan del alma vegetativa a la sensitiva ${ }^{76}$. No trata el tema directamente y lo que se nos ofrece como una posibilidad es la vía de deducción de otros textos suyos - sobre la diferencia substancial, por ejemplo - como se podría aplicarlo al embrión humano. En caso del embrión no se puede mantener la identidad substancial, pues el corruptio aniquila la forma sustancial anterior. Tampoco puede admitirse la identidad numérica entre el embrión

74 In IV Sent., 1, 2, 6 qc 2, ad 2.

75 In IV Sent., d.44, q.1, a.2, qc 4; cfr. F. Amerini, Tommaso..., op. cit., 185.

76 Cfr. A. G. Wilson, G. A., Thomas Aquinas and Henry of Ghent on the Succession of Substantial Forms and the Origin of Human Life. "Proceedings of the American Catholic Philosophical Association" 64 (1990) 117-131. 
y el hombre, pues a modo paralelo rechaza santo Tomas dicha identidad entre el grano, semilla y la planta que nace de este grano ${ }^{77}$. No es esta la relación que puede establecerse. Mas bien el camino para fijar la identidad del embrión pasar por la distinción tan importante para la metafísica que es entre "potencia" y "acto".

Tomas aunque rotundamente recuerda que no es posible hablar del perfeccionamiento de una forma substancial, esto no niega que mantenga una visión de la identidad del embrión. El embrión en sus primeras frases caracteriza una identidad del mismo sujeto, ídem subiectio que puede ser descrita como la genérica (genus). Esta identidad se puede deducir de la sustitución de las funciones del embrión que describe en términos del perfeccionamiento. El dicho proceso de generación es dirigido por el fin que es el ser hombre, lo cual permite ver, utilizando la terminología tomista, en el embrión el hombre in potencia. La potencia y el acto requieren a un sujeto. En el De Virtutibus se describe este proceso de pasar de la forma imperfecta a la perfecta como el de la progresiva actua$\operatorname{lidad}^{78}$. En proceso de generación, el mismo sujeto debe haber desde el inicio hasta el final. Esto explica que el embrión desde el principio puede considerarse humano y mantiene su identidad durante todo el proceso. Es un embrión humano que se diferencia del embrión del caballo, afirma santo Tomas, tanto por su mayor complejidad estructural y funcional, como por su propia identidad ${ }^{79}$. De ahí que el concepto de la "personalidad embrionaria", término introducido por John R. Meyer, gana cada vez más terreno ${ }^{80}$.

A título de resumen, resultan muy esclarecedoras sus palabras de la Suma de teología, donde en marco de la consideración de la transmisión del pecado original, aclara la vía por la que el embrión recibe desde primer momento la naturaleza humana: "Aunque el alma no sea transmitida (por generación), ya que la virtualidad del semen no puede producir un alma racional, sin embargo, (el semen) coopera dispositivamente a la misma. De ahí que, por la virtualidad del semen, se transmita la naturale-

\footnotetext{
In IV Sent., d.44, q.1, a.1, qc 1, ad 1.

De Virtutibus., q. 1, a. 11.

De Potentia, q.3, a.10.

80 Cfr. J. R. Meyer, Embryonic Personhood, Human Nature and Rational Ensoulment, “The Heythrop
} Journal" 2 (2006) 206-225. 
za humana del padre al hijo y, simultáneamente con la naturaleza, la infección de la misma; puesto que el que nace se hace partícipe de la culpa del primer padre por recibir de él su naturaleza por una cierta moción, que es la generación"

De esta continuidad del sujeto, a pesar de la discontinuidad de las formas que sufren el remplazamiento, surgen varias implicaciones éticas y un respeto al embrión desde el inicio. Aunque formalmente, materia y forma embrional antes de la animación racional no son humanas, sin embargo son dispositio hacia la materia y forma humana y por eso mismo permiten hablar de requerida continuidad del sujeto, un cierto continuum de la vida, aunque de diferentes grados, pero único e irreversible con una teleología de fondo que le identifica indudablemente.

Respecto a la pregunta por la personalidad del embrión, cuando empieza, si en la concepción o animación, se ha dado respuestas que podríamos agrupar en dos. Por un lado, la postura mantenida por Robert Passnau que sigue literalmente el texto del Aquinate y marca el inicio de ser persona cuando aparece el celebro que capacita al hombre a ejercer las operaciones propias de la personas ${ }^{82}$. No comparten esta tesis, John Haldane y Patrick Lee, quienes sitúan en la concepción el inicio de la personalidad humana: el embrión como una totalidad ("organismo") es capaz del propio desarrollo ${ }^{83}$. Es importante notar que el concepto de persona no se identifica con "tener alma", tiene sentido más amplio: anima mea non est ego, afirma santo Tomas ${ }^{84}$. El ser persona no puede reducirse a unas actividades del alma ${ }^{85}$ y por tanto al preguntar por la personalidad del embrión se exige unas perspectivas mas amplias que abarquen la cuestión de naturaleza humana y el vínculo cuerpo - alma ${ }^{86}$.

\footnotetext{
${ }_{81}$ S. Th., I-II, q.81, a.1, ad 2.

82 R. Pasnau, Thomas Aquinas and Human Nature: A Philosophical Study of Summa Theologiae 1a, 75-89, Cambridge 2001.

83 J. Haldane, P. Lee, Aquinas on Human Ensoulment, Abortion, and the Value of Life: Reply to Robert Pasnau, "Philosophy" 78 (2003) 532-540. Cfr. tambien: D. Bradley, To Be or Not to Be?: Pasnau on Aquinas's Immortal Human Soul, “The Thomist” 68/1 (2004), 1-40.

84 In I Cor., cap. XV, lect. 2.

85 Cfr. comentarios de B. Davies, The Thought of Thomas Aquinas, Oxford 1992, 213-214.

86 G. Klima, Man=Body+Soul: Aquinas's Arithmetic of Human Nature, en B. Davies (ed.), Thomas Aquinas: Contemporary Philosophical Perspectives, Oxford 2002, 257-273.
} 
En el debate puede ser muy útil considerar detalladamente lo que entiende santo Tomas por la nativitas in utero. Como ya hemos mencionado antes es un término que designa la concepción humana. Al hacer la referencia a esta distinción, en el comentario a Job el Aquinate observa que existen dos estados de vida. El primero es "oculto" que se refiere a los concebidos que viven in útero, el otro "manifiesto que lo viven los hombres después de haber nacido de útero". El Aquinate habla aquí de modo general del conceptio, lo cual supone una cierta continuidad entre los concebidos y nacidos. Ha de subrayarse que no se refiere al momento de animación racional, sino a la conceptio humana ${ }^{87}$. En la misma línea podemos comprender la afirmación de santo Tomas que al referirse al nacimiento in útero lo percibe como el momento, cuando homo a Deo creatus, formatus est ${ }^{88}$.

\section{Algunas cuestiones de la embriogenesis humana}

Al final de nuestra reflexión nos detendremos en cuestiones puntuales de la embriogénesis humana que pueden ser interesantes tanto para la bioética contemporánea, como demuestran una consciencia y visión integral de la vida del embrión en diferentes fases.

\section{1. ¿Como se transmite la similitud?}

Otro tema interesante que podemos deducir de los textos de santo Tomas es su consciencia del tema de la transmisión de los rasgos que caracterizan a los padres y pasan a los hijos (ex patre transire). Al hilo de la discusión sobre la justicia humana que no castiga a los hijos por las culpas de los padres, aunque las consecuencias de su mala conducta pueden per accidens afectar a los hijos, Tomas constata que ex truncatis truncatus nascitur ${ }^{89}$. Se

87 In Iob, cap. 3: "Postquam diei nativitatis et nocti conceptionis suae maledixerat ut ostenderet initia suae vitae se abhorrere, nunc ostendit se abhorrere suam conservationem in vita, ut ex his manifestius ostendat quod vita eius est ei onerosa. Est autem duplex status vitae: unus occultus quo concepti vivunt in utero, alius manifestus quo vivunt homines post nativitatem ex utero".

88 In IV Sent., d. 6 q. 1 a. 1 qc. 2 ad 1.

89 In II Sent., d. 33 q. 1 a. 2 ad 4. 
trata de heredar unos rasgos que son transmitidos por el semen masculino y particularmente por su potencia generativa. Naturalmente, esto tiene su explicación en la regla de la que trata en Suma de teología: "el que engendra, engendra un ser de su misma especie. A veces, sin embargo, se dan diferencias accidentales entre el que engendra y el engendrado, debidas a la materia o a la debilidad de la potencia generativa" ${ }^{90}$. Por tanto, la raíz de cualquier deformación en el embrión se esconde en la debilidad del semen que provoca las anomalías, por esto "la pierna que nace rota por la debilidad del semen, inmediatamente empieza a cojear"91.

Esta virtus formativa se queda durante todo el proceso de generación, aunque no precisa que pasa con ella cuando llega el alma racional: en la De Potencia dice que cambia su función ${ }^{92}$. En la Suma, escrita después, parece revisar el Aquinate su posición: niega la virtud esta sea el alma del hombre ${ }^{93}$.

\subsection{Patologías del embarazo}

Santo Tomas considera también la situación en la que sufre algún órgano del embrión ya formado por la forma racional. La lesión, aunque grave y si toca incluso el celebro, no afecta a la esencia del ánima. Se mantiene la substancia rei, pues no afecto al principio (por ejemplo de la vista), sino a los órganos que pueden ser reparados o sustituidos per artem ${ }^{94}$. De ahí viene la convicción del Aquinate que el ser persona no se reduce al uso de la razón, sino a la capacidad que puede ser realizada de forma más o menos perfecta ${ }^{95}$, o no realizarse ${ }^{96}$.

En general el tema de las patologías del embarazo está presente al hilo de las cuestiones filosóficas, cuando por ejemplo en De Veritate considera el modo de cómo algunas cosas pueden transformarse gracias a su propia

${ }_{90}$ Cfr. S. Th., III, q.74, a.3, ad 2: 2: "generans generat sibi simile in specie, fit tamen aliquando aliqua dissimilitudo generantis ad genitum quantum ad accidentia, vel propter materiam, vel propter debilitatem virtutis generativae".

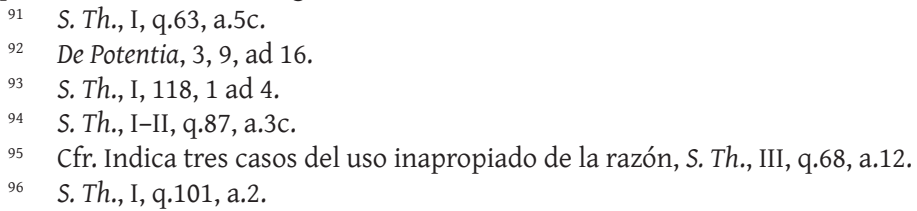


fuerza ${ }^{97}$. Uno de los casos es la aparición del fetus monstruosus como consecuencia del defecto de la propia virtud formativa del semen. Ya desde el comentario a las Sentencias, santo Tomas ubicaba la raíz de las patologías de feto en la deficiencia del semen y su incorrecto funcionamiento. De ahí que cuando se corrompe el llamado 'movimiento del padre en semen' que de su naturaleza mueve hacia lo más similar a el, entonces el hijo se parece mas a los abuelos o bis-abuelos que al padre ${ }^{98}$.

\subsection{Aborto}

La sensibilidad del santo Tomas a la vida le lleva a denunciar el aborto como pecado grave, aunque hace una distinción: "El que hiere a la mujer embarazada hace una cosa ilícita, y, por esta razón, si de ello resultase la muerte de la mujer o del feto animado, no se excusa del crimen de homicidio, sobre todo cuando la muerte sigue ciertamente a esa acción violenta"99.

Como se ha observado, santo Tomas distingue entre un embrión informado (sin el alma racional, inanimatus) y el feto formado (puerperitus animatus), pero esto no implica que se puede abortar antes de recibir el alma por el embrión ${ }^{100}$. Aunque no se puede llamar "homicidio", sin embargo constituye para santo Tomas un grave pecado ${ }^{101}$. El aborto por excelencia es un pecado contra naturam, pues como dice el Aquinate ninguna especie animal (incluso bestiae) hace esto ${ }^{102}$. En otro texto, del comentario a la Primera Carta al

${ }_{97}$ Cfr. De Veritate, q. 13 a. 1c.: [...] sicut cum ex defectu virtutis formativae in semine generatur fetus monstruosus.

98 In II Sent., d. 30 q. 2 a. 2 ad 4: "Ad quartum dicendum, quod assimilatio non est propter convenientiam in materia; sed propter motum virtutis activae, quo movet in suam similitudinem: et quia aliquando corrumpitur motus patris in semine, nascitur filius similis avo et proavo, cujus motus manet, ut 18 de animalibus philosophus ostendit; et non propter hoc quod materia corporis nati ex avo et proavo traducatur".

99 S. Th., II-II, q.64, a.8 ad 2.

100 Cfr. N. Jouve, El manantial de la vida. Genes y bioética, Madrid 2012, 145. El autor recuerda la historia del llamado "caso Warnock" desde las tesis de Norman Ford, y luego J. McLaren, quienes mantenían que hasta decimocuarto día del embarazo se debía hablar mas bien del "preembrion".

101 ScG, lib. III, cap.122.

102 In IV Sent., d.31, q.2, a.3: "Hoc peccatum quamvis sit grave, et inter maleficia computandum, et contra naturam, quia etiam bestiae fetus expectant; tamen est minus quam homicidium; quia adhuc poterat alio modo impediri conceptus. Nec est judicandus talis irregularis, nisi jam formato puerperio abortum procuret". 
Timoteo, identifica el aborto con la supresión de la vida embrional (que es humana en potencia) ${ }^{103}$. Tomas utiliza la palabra occidere y nos distingue entre un embrión animado y no animado, al parecer optando por la aceptación del ídem subiecto, la identidad del sujeto que esta in via perfectionis.

Para santo Tomas, el aborto es en plano ético una intervención ilícita, en plano ético, porque interrumpe un proceso natural que conduce hacia la vida humana, pero todavía mas fuerte suena su valoración, cuando trata el aborto como maleficium y lo iguala con el homicidio. Por otro lado, en una de las descripciones del pecado de homicidio, siguiendo a san Agustín, afirma que es "la occisión de un inocente" 104 , lo cual de alguna manera permite hablar de embrión en si mismo, sin defensa propia. No obstante, las distinciones que hace santo Tomas muestran que la protección de la vida humana es universal, aunque diferenciada. Esto tiene su repercusión a la hora de decidir, por ejemplo, cuando ocurre un conflicto entre el bien de la madre y el del embrión - para santo Tomas no cabe duda que hay que elegir el de la madre ${ }^{105}$.

\section{Conclusiones}

Lo primero necesario es estar sensible al significado del pensamiento de santo Tomas en su contexto originario y atento si mantendría santo Tomas su postura hoy en día, de la animación humana retardada, conociendo los datos biológicos o no ${ }^{106}$. Algunos investigadores, como J. Eberl, subrayan que los principios metafísicos del Aquinate sirven de buena base para pensar que el momento de la concepción es el de la animación y comienzo del ser personal del hombre ${ }^{107}$. Es un argumento que ya sacaban los tomistas a partir de Domingo Báñez ${ }^{108}$.

103 In 1 Tim, cap. V, lect. 2.

104 S. Th., I-II, q.88, a.6, ad 3.

105 In IV Sent., d.6, q.1, a.1, qc 1, ad 4.

106 F. Amerini, Tommaso..., 241-256.

107 J. Eberl, A Thomistic Perspective on the Beginning of Personhood:Redux. "Bioethics" 21/5 (2007) 283-289.

108 Cfr. J. A. García Cuadrado, Origen y principio del alma humana: la interpretación de Domingo Báñez, en: C. González Ayesta (ed.), El alma humana: esencia y destino. IV Centenario de Domingo Báñez (1528-1604), Pamplona 2006, 107-142. 
Lo que destaca en sus reflexiones es no tanto explicar todos los detalles del proceso de la generación - basta recordar que muchas de las cuestiones analiza al hilo de otros temas, especialmente teológicas - sino ofrecer una idea general, base antropológica, para explicar cuestiones éticas concretas. En sus distinciones no se puede ver a un biólogo, sino a un teólogo sensible a todas las formas de la vida.

El embrión para santo Tomas se constituye metafísicamente después de que el semen masculino ha actualizado la potencialidad a la vida y se ha mezclado con la materia que dispuso la mujer. El embrión desde el primer momento tiene una forma para ejercer las operaciones vitales, primero vegetativa, luego sensitiva y la forma racional llega la final del proceso de la concepción.

\section{Summary}

The Life of Embryon According to Thomas Aquinas

It is very popular among scholars to reduce the question of medieval embryology only to so called "delayed animation", with a little reference to important philosophical background of the topic. This article present the concept of "life" in the perspective of thomistic doctrine, especially putting the emphasis on the issue of the soul as the principle of life and what does the virtus generativa means for Aquinas. He exposes in six stage of embryogenesis, which we can discover in his writings, the identity of the embryo in all process of his development. The changes of substantial forms, from vegetative one to human's form, is contemplated by Aquinas in logical, not chronological order. That's why for saint Thomas the abortion is considerate always as heavy moral offense contra naturam. For the integral understanding of Thomas's view on the status of human embryo is important to take account of christological themes.

Keywords: Thomas Aquinas, delayed animation, embryo, medieval embryology 